\title{
TEORIA DA ESTRUTURAÇÃO E AS NOVAS SOCIOLOGIAS: PROVOCAÇÕES TEÓRICO-METODOLÓGICAS EM ANTHONY GIDDENS
}

Marcos Murelle Azevedo Cruz ${ }^{1}$

Resumo: A pesquisa, de caráter bibliográfico, apresenta uma síntese das principais contribuições da chamada teoria da estruturação do sociólogo inglês Anthony Giddens para as ciências sociais, elaborada a partir de influências teóricas que ele recebeu ao longo de sua trajetória acadêmica, como pesquisador social. No primeiro momento, o trabalho recapitula, de modo breve, as principais contribuições do pensador para a explicação da vida social moderna, a partir de duas categorias analíticas que ele chamou de ação e estrutura, procurando entender como ocorre a participação dos atores sociais no contexto de mudanças da sociedade. Na sequência, serão apresentadas as possibilidades de abordagem de sua teoria com incursões breves no campo da religião, confrontando os principais limites de sua abordagem teórica para estudos empíricos, mesmo que toda teoria sociológica esteja, de algum modo, aberta a críticas e revisões constantes, como atestam seus escritos.

Palavras-chave: Ação. Estrutura. Atores sociais.

Riassunto: La ricerca, di carattere bibliografico, presenta una sintesi dei principali contributi della cosiddetta teoria strutturante del sociologo inglese Anthony Giddens alle scienze sociali, elaborata dalle influenze teoriche che ha ricevuto durante la sua traiettoria accademica, come ricercatore sociale. All'inizio, il lavoro esamina brevemente i principali contributi del pensatore alla spiegazione della vita sociale moderna, sulla base di due categorie analitiche che ha chiamato azione e struttura, cercando di capire come la partecipazione degli attori sociali nel contesto cambiamenti nella società. Nella sequenza, saranno presentate le possibilità di avvicinarsi alla sua teoria con brevi incursioni nel campo della religione, confrontando i limiti principali del suo approccio teorico agli studi empirici, anche se tutta la teoria sociologica è, in qualche modo, aperta a critiche e revisioni costanti, come attestano i loro scritti.

Parole chiave: azione, struttura. Attori sociali.

\footnotetext{
${ }^{1}$ Doutorado (em andamento) em Ciências Sociais no Programa de Pós-Graduação em Sociologia e Antropologia da Universidade Federal do Pará (PPGSA/UFPA). É docente no Departamento de Filosofia e Ciências Sociais da Universidade do Estado do Pará. E-mail: marcosmurelle@gmail.com
} 


\section{Considerações iniciais}

A proposta inicial deste trabalho é apresentar uma breve síntese sobre os principais conceitos da Teoria da Estruturação de Anthony Giddens, mostrando a repercussão de suas contribuições para a sociologia. A constituição da obra deste importante sociólogo inglês se estrutura em quatro etapas bem distintas. A primeira ocorre entre os anos de 1971 a 1975 e a principal publicação deste momento é Capitalismo e Moderna Teoria Social (2005) obra em que apresentou uma análise acerca dos três grandes teóricos da sociologia clássica: Karl Marx, Émile Durkheim e Max Weber. No segundo momento entre os anos de 1976 a 1984, Giddens desenvolve sua própria síntese teórica que ficou conhecida como Teoria da Estruturação, com a publicação de duas importantes obras: Novas Regras do Método Sociológico (1978) e a Constituição da Sociedade (2003). O terceiro período, de 1981 a 1994 corresponde à formulação das teorias sobre a Modernidade e a globalização, amplamente discutidas em As Consequências da Modernidade (1991) e Modernidade e Identidade (2002). No quarto momento, o sociólogo se debruça sobre temas relacionados à política e ao meio ambiente nas obras Para além da esquerda e da direita (1996) e A terceira via (1998).

Para este estudo, vou me limitar ao segundo e ao terceiro momento da obra de Giddens respectivamente, apresentando uma breve síntese sobre a Teoria da Estruturação e seus impactos sobre as teorias da modernidade e da globalização, aplicados ao estudo da religião. É bom esclarecer uma vez mais que a Teoria da Estruturação possibilitou avanços significativos na superação da polêmica de Parsons e Foucault acerca do poder e dos determinismos dos sujeitos. Como toda teoria sociológica está aberta à revisão, o próprio Giddens formula uma crítica em reposta a esses dois teóricos, mostrando que a concepção de poder, tanto num quanto no outro, não podem ser deterministas, considerado o contexto de transformação das sociedades modernas partindo da questão da subjetividade, essa estrutura interna dos sujeitos onde,

"O eu não é uma entidade passiva, determinada por influências externas; ao forjar suas auto-identidades, independente de quão locais sejam os contextos específicos da ação, os indivíduos contribuem para (e promovem diretamente) as influências sociais que são globais em suas conseqüências e implicações" (GIDDENS, 2002, p. 9). 
O modo como os atores são avaliados por suas próprias ações, demostra que uma das características fundamentais do pensamento sociológico é a revisão constante de suas proposições de análise das diferentes construções da vida social. O devir metodológico nas ciências sociais busca responder, em grande parte, aos problemas teórico-metodológicos herdados dos binarismos nas abordagens clássicas da sociedade: idealismo/materialismo, sujeito/objeto, objetivismo/subjetivismo, antinomias clássicas que se contrapõem no campo de lutas na explicação da vida social entre o "natural" e o "construído".

Nos passos das novas sociologias que concebem uma reflexão sobre as sociedades como entes em constante estado de mudanças, é possível identificar um movimento teórico protagonizado por Anthony Giddens, mas não somente por ele, que busca mostrar proposições teóricas que revelam "passagens" da dimensão objetiva à subjetiva, da individual à coletiva, que entrecruzam dimensões subjetivas e interacionais na vida social. Para Giddens (2002, p. 10) “a vida social moderna é caracterizada por profundos processos de reorganização do tempo e do espaço, associados à expansão de mecanismos de desencaixe - mecanismos que descolam as relações sociais de seus lugares específicos, recombinando-as através de grandes distâncias no tempo e no espaço”. A proposta do ensaio é esclarecer, à luz da teoria da estruturação, o envolvimento da reflexividade nas ações e nas práticas sociais dos sujeitos no espaço e tempo, examinando as repercussões de suas contribuições e os limites das abordagens.

Portanto, no primeiro tópico apresentarei uma breve síntese sobre da Teoria da Estruturação, acentuando a relação entre ação e estrutura. A partir dos conceitos-chave, discutirei no segundo tópico como essas teorias impactam nas análises sobre modernidade e globalização, no que se refere aos estudos sobre religião. Por fim, e com as devidas ressalvas, mostrarei no terceiro tópico, as possibilidades e os limites dessas teorias, identificando seus problemas de aplicabilidade em pesquisas empíricas.

\section{Perfazendo os caminhos da teoria da estruturação}

Elaborada a partir de uma abordagem eminentemente analítica, Giddens propõe uma Teoria da Estruturação que consiste na dualidade entre "ação" e "estrutura" que concebe os atores individuais como sujeitos dotados de capacidade reflexiva, em condições de alterar, a qualquer momento, os propósitos de suas ações e seus impactos 
na vida social. Tal movimento de mudança caracteriza o universo social como espaço de interações, em permanente estado de revisão, aonde as relações são recombinadas em sociedades dinâmicas e organizadas a partir de uma dualidade estrutural, o demarcador de sentidos e de diferentes significados a partir da construção de espaço e tempo.

Em seu núcleo de análise, o sociólogo inglês ocupa-se em investigar a "ação" desenvolvida pelos agentes individuais sob a influência de outros atores sociais e, por conseguinte, como a "estrutura" impacta, de modo determinante, nas ações de outros agentes. Desse modo, ação e estrutura constituem o pólo no qual ocorre o movimento dialético objetivo-subjetivo, fundamental na dinâmica social. Assim sendo, para Giddens (2003) o que torna as sociedades dinâmicas é justamente sua capacidade interacionista, isto é, o modo ativo como os agentes participam das mudanças de condições a partir da ação. As condições materiais, políticas e a história de uma dada sociedade podem mudar na medida em que os sujeitos tem mais ou menos consciência de suas ações, ainda que parcial, haja vista que há sempre um descompasso entre ação e racionalidade e destas com a consciência do agente.

Os atores são sempre reflexivos, com comportamentos abertos à revisão, permitindo a sociedade um constante estado de mudanças. Contudo, a ação nem sempre supõe a racionalidade, motivo pelo qual Giddens subdivide a consciência em "prática" e "discursiva". Respectivamente, a consciência possui uma dimensão prática, assimilada espontaneamente pelos agentes em diferentes formas de interação, que dispensa uma explicação mais elaborada dos sentidos dos comportamentos, justamente por serem espontâneos e, por serem assimilados nas diferentes experiências de interação no convívio social. Já a "consciência discursiva", por sua vez, requer o pensamento elaborado, que dê conta de explicar discursivamente porque os agentes se comportam de determinado modo, esclarecendo as motivações, causas e efeitos de determinadas ações.

As estruturas são organizadas a partir de interações, de conjuntos de ações realizadas, de modo a produzir certas condições e resultados pelos próprios agentes, pois " a ação humana ocorre como duree, um fluxo continuo de conduta, à semelhança da cognição. A ação intencional não se compõe de um agregado ou uma série de intenções, razões e motivos isolados" (GIDDENS, 2003, p. 3). Tal proposição pode significar que no núcleo da teoria da estruturação, a junção entre "ação" e "estrutura" suponha uma "reflexividade" segundo a qual o agente não somente é afetado, como também participa das ações desenvolvidas com outros agentes por meio de processos 
interacionais que, por sua vez, mostram como a construção social da realidade pode ser explicada não "de fora”, mas na racionalização da ação, "entendida aqui mais como um processo do que como um estado, e como inerentemente envolvida na competência dos agentes. Uma ontologia de tempo-espaço como constitutiva de práticas sociais é básica para a concepção de estruturação, a qual começa a partir da temporalidade e, portanto, num certo sentido, da "história"” (GIDDENS, 2003, p. 4).

A racionalização da ação dentro da diversidade das circunstâncias constitui o elemento-chave para compreender como as práticas dos atores são avaliadas por outros atores. Para Giddens (2003) a racionalização da ação dos atores tem a ver com uma reflexividade que de um lado, não tem o controle da consciência de significados dessas ações, visto que elas integram um conjunto de conhecimentos que são praticados naturalmente pelos agentes sociais, mas de outro lado, evocam um sentido necessário ao fluxo natural da vida social.

Com efeito, o “conhecimento mútuo incorporado" (2003, p. 5) a que Giddens se refere, tem a ver com a ideia de que, embora os atores tenham reflexividade naturalmente manifesta nas ações, seja pela recorrência, seja pela repetibilidade dos comportamentos, nem sempre o conhecimento sobre eles está no domínio total da consciência. Assim, ao retomar a categoria de "inconsciente" de Freud para explicar a dimensão obscura da ação, Giddens mostra que as ações também participam de uma dimensão desconhecida, isto é, que os agentes que as praticam podem alternar os seus sentidos ora pelo consciente, ora pelo inconsciente. Mas Giddens não mostra como isso acontece e quais são os desdobramentos das suas proposições sobre as consequências (im) pensadas advindas destas ações inconscientes.

Por outro lado, o que há em certo sentido para Giddens (2003, p. 6) é o “monitoramento reflexivo da atividade”, uma ação objetiva, calculada, cujos resultados sejam previsíveis, como bem expressou na definição: "por racionalização da ação entendo que os atores - também rotineiramente e, na maioria dos casos, sem qualquer alarde - mantém um contínuo "entendimento teórico" das bases de sua atividade" (Idem, 2003, p. 6). Nesse contexto, é esperado que os agentes quando indagados sobre as motivações de determinadas ações, sejam capazes de explicitar, de modo discursivo, as razões objetivas que motivaram determinadas práticas sociais.

Do ponto de vista hermenêutico, a interpretação das ações desses atores sociais podem ser decifráveis desde que a descrição ou detalhamento dessas atividades sejam 
providas de certa "familiaridade" com "as formas de vida expressas naquelas atividades" (GIDDENS, 2003, p. 3). Essa familiaridade é possível em razão dos comportamentos recorrentes que os sujeitos expressam em suas práticas sociais que, por sua vez, são apreendidos pela "cognoscitividade” de um modo objetivo, que racionaliza a vida, tornando possível uma reflexividade sobre ela. No entanto, essa visão descuida das percepções que são captadas pelas subjetividades, de modo que não sejam explicadas somente por elas mesmas, mas pela recorrência, reflexão e racionalização, tendo em vista que é a partir delas que o sujeito prevê, calcula e racionaliza suas ações.

Assim, é possível concluir que a teoria da estruturação em Giddens (2003) mostra que os sujeitos são "conhecedores" parcial ou totalmente das suas ações. A percepção dos agentes atuantes na relação com as suas práticas sociais dentro e fora dos espaços institucionalizados, situa a sua teoria num universo teórico e prático possíveis, que não obstante suas limitações operam a junção entre objetividade-subjetividade.

Para Ortner Sherry (2007) as proposições de Giddens acerca de uma "teoria da prática", bem como os estudos feitos por Bourdieu (2004) ao tratar sobre a definição de habitus em que os sujeitos internalizam as experiências do mundo externo tanto as influências definidas culturalmente como as objetivamente reais, ajudam a inferir como as novas sociologias especialmente a proposição de Giddens buscam uma visão de agente como alguém "existencialmente complexo, um ser que sente e pensa e reflete que faz e busca significado" (ORTNER, 2007, p. 379). Essas novas sociologias prepõem justamente um rompimento com a perspectiva clássica durkheiminiana da ideia de estrutura como fator preponderante sobre o sujeito, ao passo que busca distanciar-se da dicotomia entre sujeito e estrutura; capturar a dialética e mesmo a relação entre objetividade-subjetividade nas redes de relações e de sensibilidades resultantes de uma dialética entre o sujeito e as estruturas sociais, como ocorre no campo dos estudos da religião. Sendo uma construção social, a religião também participa de mudanças importantes no contexto do mundo globalizado, onde a relação com o sagrado é ressignificada a partir das transformações operadas pelo capitalismo.

\section{A atitude religiosa, a racionalidade moderna e existência.}

Nos estudos históricos sobre capitalismo e religiões mundiais, a teoria social da modernidade caracterizou a religião como sendo um dos aspectos centrais da vida das 
sociedades, não somente pela riqueza de seus símbolos e cerimônias, mas por sua diversidade de experiências na quase totalidade dos povos e culturas, pelo menos daqueles que se têm registros. Definindo, a religião é o "conjunto de símbolos que invocam sentimentos de reverência ou de temor, ligados a rituais ou cerimónias (como os serviços religiosos) realizados por uma comunidade de crentes. Cada um destes elementos deve ser alvo de explicação. Quer as crenças numa religião envolvam deuses, ou não, existem sempre seres ou objectos que inspiram atitudes de temor ou de admiração” (GIDDENS, 2008, p. 535).

No mundo moderno, a atitude religiosa e o pensamento racionalista coexistem num espaço de constantes tensões, contrapondo duas visões bem distintas. De um lado, a ideia de que o pensamento racionalista, idealizado a partir de um projeto de emancipação, deixou de considerar questões fundamentais como o sentido da existência e um propósito para a vida. Por outro lado, a religião com seus dogmas, seria a possibilidade pela qual os homens encontrariam algum alento que fosse capaz de atenuar as agruras e as precariedades da sua existência humana.

A questão colocada então é, qual o lugar da religião na era moderna, quando as análises sobre mundo globalizado mostram que tanto as promessas da ciência como as certezas da religião estão naturalmente abertas à revisão, quando a dúvida “característica generalizada da razão crítica moderna, permeia a vida cotidiana assim como a consciência filosófica, e constitui uma dimensão existencial geral do mundo social contemporâneo" (GIDDENS, 2002, p. 10). As disciplinas inauguram modos diferentes de narrar sobre as origens dos homens e os impactos de suas ações nas sociedades. O funcionamento da natureza e as origens do universo passam a ser explicados a partir de relações entre causa e efeito, que não precisam necessariamente de uma relação direta com as narrativas religiosas para serem consideradas verdadeiras.

Desde então, as instituições religiosas, não obstante suas relações com o transcendente, por meio de sistemas de crença e códigos morais, passam a ser reconhecidas como construções humanas, abrindo possibilidades para outras formas de interpretação não religiosa acerca das origens. Com isso, a fé no Deus criador do pensamento judaico-cristão, condivide suas certezas com a uma pluridiversidade de outras possíveis explicações das origens do homem e do mundo, como ocorre com o evolucionismo. Para Giddens (2002, p. 9) as "instituições modernas diferem de todas as formas anteriores de ordem social quanto a seu dinamismo, ao grau em que interferem 
com hábitos e costumes tradicionais, e a seu impacto global". Portanto, se considerarmos as interpretações mais contemporâneas da teoria social, a religião deixou de ser, desde algum tempo, a força central da vida social, fator impulsionado em grande medida, pelo progresso da ciência e da industrialização europeia.

A complexidade da vida moderna requer que "ao analisarmos as práticas religiosas, temos de interpretar crenças e rituais muito diferentes dos que encontramos em várias culturas humanas. Temos de ser sensíveis aos ideais que inspiram convicções profundas aos crentes, e de manter simultaneamente uma visão equilibrada dos mesmos" (GIDDENS, 2008, p. 535). Ainda acerca dos modos de conduta praticados pela religião, é preciso reconhecer que, não obstante seus diferentes significados, esta pode ser portadora de um conjunto de motivações que tendem tanto para busca do eterno, como para atingir objetivos mundanos: acúmulos, vantagens financeiras, etc.

Para Giddens (2008, p. 535) é preciso "reconhecer a diversidade das crenças religiosas e dos modos de conduta, mas devemos igualmente analisar a natureza da religião como fenómeno de carácter geral”. O estudo da religião continua sendo uma das mais importantes tarefas que colocam outras questões à imaginação sociológica.

\section{As possibilidades e os limites da teoria da estruturação no contexto das novas sociologias}

As contribuições para a sociologia reflexiva podem ser vislumbradas no modo como Giddens articula as concepções de "espaço" e "tempo" para explicar as transformações das sociedades modernas, ideias e articulações amplamente debatidas em suas obras As Consequências da Modernidade (1991), As Transformações da Intimidade (1993), e Modernidade e Identidade (2002). A partir de suas incursões teóricas, o debate da sociologia busca superar, em grande parte, suas matrizes teóricas de tradição evolucionista cujos núcleos de análise estavam fortemente influenciados pelo evolucionismo biológico e pelo marxismo. Dentre os méritos de suas proposições analíticas, constam as análises sobre sociedades modernas em transformação vertiginosa, ao apresentar as continuidades da história humana, enfatizando o descolamento de espaço e tempo históricos. Além disso, mostra como as sociedades modernas se tornaram lugares hostis, em razão do profundo processo de mudança que comporta todos os riscos e apostas possíveis das relações sociais. De fato, em suas análises é possível vislumbrar em que ponto as sociedades modernas são fortemente 
marcadas por mudanças de percurso, por uma era de desencaixes, de fruições históricas descontínuas, de reexames de estatutos rígidos do conhecimento científico na sua relação com a sociedade, com teorias que possibilitam reflexividade das ações sociais.

A crítica ao evolucionismo biológico enfatizado por Giddens foi decisiva na mudança de rumos da sociologia, pois reconheceu importância à história na sua relação temporal com a ação dos agentes. Corcuff (2001, p. 83) apresenta a questão de fundo da crítica, mostrando que de fato "um dos perigos do evolucionismo é o que ele chama de 'compreensão unilinear', que reduz a uma única linha de evolução geral os movimentos próprios às sociedades humanas”. Sinalizadas as suas contribuições, seu debate teórico em torno de uma moderna teoria social apresenta alguns limites e pontos obscuros.

O primeiro limite da teoria da estruturação de Giddens é o problema do real/irreal que está relacionado à memória, isto é, a ideia que considera a estrutura como algo real, mas, ao mesmo tempo, virtual, gravado na memória dos agentes da ação como que por meio de esquemas mentais assimilados a partir de condições e regras da estrutura que, por sua vez, são recursos necessários para a ação, e sem os quais elas seriam inexistentes. Ocorre, todavia, que as realidades sociais são substanciadas a partir de traços sociais da memória que estão dentro e não fora das estruturas, ou no "não lugar" do tempo e do espaço históricos, muito embora sejam reificados. Com efeito, aceitar o seu posicionamento a partir de tal proposição seria como que admitir que os sistemas sociais sejam como instâncias metafenomênicas, quando na verdade, o debate sobre as condições dos sistemas sociais não deve encerrar em antinomias de homogêneo-heterogêneo, como parece indicar no debate sobre a memória social.

Outro ponto diz respeito ao caráter simbólico amplamente indicado por Bourdieu em suas obras, e que Giddens considera de uma forma quase despercebida no debate sobre os interacionismos nas ações dos agentes individuais. Para o sociólogo da estruturação, o poder existe na sua relação com os agentes que tencionam as estruturas a partir de objetividades, na junção entre ação e estrutura. Assim, sobressai o caráter eminentemente teórico da sua proposição, a despeito da ideia de que suas contribuições estão mais numa ordem analítica do que prática, o que pode apresentar problemas de aplicação da teoria em estudos empíricos.

O terceiro limite da teoria da estruturação refere-se ao denso tratamento na dualidade ação e estrutura, mas que descuidou dos interacionismos simbólicos. Enquanto Giddens deu a tônica da explicação da dualidade da estrutura, suas discussões 
não alcançaram de modo mais elucidativo o lugar da dimensão coletiva nas interações sociais que, ao que tudo indica, ficou em segundo plano em sua teoria. Como bem acentuou Domingues (2003, p. 67) "mesmo o conceito de sistema social, e particularmente a ação social em seu plano coletivo, não recebe um tratamento adequado e comporta-se, em seus escritos, como um conceito meramente coadjuvante dos de ação individual e estrutura". Parece que tal posição resvala na sua metodologia em tom de proposições analíticas, de caráter mais individual do que coletivo.

\section{Conclusões}

Gostaria de apresentar algumas conclusões acerca da teoria da estruturação, focando em alguns problemas de fertilidade empírica e de fundamentação teórica, principal alvo dos críticos de Giddens. O primeiro diz respeito sobre como a teoria da estruturação pode ser utilizada para interpretar dados de pesquisa e o problema parece que está na equiparação entre os conceitos de teoria da estruturação e ontologia social. Paradoxalmente ele queria evitar que sua teoria se tornasse um conjunto de explicações para a totalidade das ações como incorreram alguns dos seus contemporâneos, ignorando situações que não se adequassem a teoria. Para Giddens (2008, p. 385) "os conceitos da teoria da estruturação, como no caso de qualquer perspectiva teórica corrente, devem ser considerados para muitos fins de pesquisa, nada mais do que recursos sensibilizadores. Quer dizer, eles podem ser úteis para se refletir sobre problemas de pesquisa e para interpretação de dados de estudo”. Em outras palavras, ao equiparar a teoria da estruturação à ontologia, Giddens quis preservá-la de determinismos.

Evidentemente que os problemas de fundamentação teórica com implicação nos estudos empíricos não desqualificam as grandiosas contribuições analíticas nos estudos sobre modernidade e globalização, tão fundamentais na compreensão das sociedades atuais. Sem esquecer as valiosas contribuições de suas releituras sobre os clássicos da sociologia Marx, Durkheim e Weber que possibilitaram novas compreensões sobre o capitalismo e história.

Nas linhas não tão conclusivas, convém recordar que o objetivo de Giddens era unificar duas importantes instâncias da vida social moderna: estrutura e agência. Com efeito, é possível notar em suas sínteses que, de um lado, há uma forte influência de 
Marx e de Althusser, e de outro, do interacionismo de Goffman e Barth. Ambas foram importantes, pois mostraram que a abordagem sobre o conceito de agencia de Giddens corroborado em outras abordagens teóricas de sociólogos e antropólogos contemporâneos como Sherry Ortner ${ }^{2}$ foram fundamentais para apresentar a imagem de um ator estratégico, dotado de um corpo, combatendo dentro dos limites impostos pela estrutura e, interagindo com os espaços de poder, e com diferentes formas de opressão, impostos aos corpos dos atores sociais. Portanto, a teoria da prática consubstanciada em face do ator estratégico e consciente de suas ações, mostrou não somente as influências das estruturas sobre os corpos, mas reforçou a ação, isto é, o ator se reconhece no campo de disputas e espaços de poder também de forma combativa.

Parece implícito a tarefa da pesquisa sociológica, nas expressões de Domingues (2004, p. 69), que "é preciso, todavia, aceitar que as ciências sociais não podem escapar às injunções do que se poderia chamar de 'teoria do cobertor curto': se se cobre a cabeça, os pés sobram, e vice-versa”. Em Giddens é possível visualizar o pensamento sociológico em estado permanente de mudanças, um imponderável ao qual nenhum teórico pode escapar que é o de apresentar as possibilidades e os limites de uma teoria para explicar a intensidade do universo social em constante estado de mudança.

\section{REFERÊNCIAS}

BOURDIEU, Pierre. O Poder Simbólico. Rio de Janeiro: Bertrand Brasil, 2004.

CORCUFF, Philippe. As Novas Sociologias: construções da realidade social. Tradução de Viviane Ribeiro. Bauru, São Paulo: editora EDUSC, 2001.

DOMINGUES, José Maurício. Teorias Sociológicas no Século XX. $2^{\mathrm{a}}$ edição. Rio de Janeiro

GIDDENS, Anthony. As consequências da modernidade. Tradução de Raul Fiker. São Paulo: Editora UNESP, 1991.

GIDDENS, Anthony. A transformação da intimidade: sexualidade, amor, e erotismo nas sociedades modernas. Tradução de Magda Lopes. São Paulo: Editora da Universidade Estadual Paulista, 1993.

GIDDENS, Anthony. Modernidade e Identidade. Rio de Janeiro: Zahar, 2002.

\footnotetext{
${ }^{2}$ Cito dois textos importantes da autora para entender melhor este debate. O primeiro é intitulado Teoria na antropologia desde os anos sessenta (2011) e o segundo é Subjetividade e crítica cultural, publicado em 2007.
} 
GIDDENS, Anthony. A constituição da sociedade. São Paulo: Martins Fontes, 2003.

GIDDENS, Anthony. Sociologia. $6^{\mathrm{a}}$ ed. Tradução de Alexandra Figueiredo Ana Patrícia Duarte Baltazar Catarina Lorga da Silva Patrícia Matos Vasco Gil. Lisboa: Fundação Calouste Gulbenkian, 2008.

ORTNER, Sherry B.. Subjetividade e crítica cultural. Horizontes Antropológicos, Porto Alegre, ano 13, n. 28, p. 375-405, jul./dez. 2007. 